\title{
Does Culture affect Consumer Behaviour, when shopping On-Line?
}

\author{
Dr. Adnane Alaoui \\ Senior Lecturer in Marketing \\ Liverpool John Moores University, United Kingdom \\ A.Alaoui@ljmu.ac.uk
}

\section{Prof. Donata Vianelli}

Full Professor of Marketing and Management

University of Trieste, Italy

donata.vianelli@deams.units.it

\begin{abstract}
On-line retailers have to decide whether to standardize or adapt their marketing strategy to the foreign consumer markets. The objective of this article is not only to locate differences in on-line shopping behavior between English, Italian, and Chinese consumers, but also to explain these differences, through cultural dimensions. A discriminant analysis was conducted on English, Italian and Chinese consumers, based on eighteen behavioral variables, to illustrate the effect that a change of culture would have on a consumer's on-line shopping behavior. The behavioral variables were classified in a descending lexicographic order of their discriminating power, between these cultures. After running the discriminant analysis, a factorial analysis of the eighteen behavioral describers was also run, to organize the latter into a smaller number of factors that are mutually exclusive, and very exhaustive. Factorial analysis identified five distinct factors that point out differences between the three countries, underlining that online retailers cannot duplicate abroad their home marketing strategy, because the needs eshoppers wish to fulfill diverge between these markets.
\end{abstract}

Keywords. Culture; Cross-cultural; On-Line shopping; Consumer Behavior

\section{Introduction and literature review}

The global expansion of firms in general and retailers in particular, has been facilitated by the development of e-commerce technologies and the growth of consumer on-line shopping in different countries. This was achieved by overcoming geographical remoteness that is often perceived as a barrier to internationalization, through increasing the efficiency of the global supply chain, and strengthening the image of global brands across different countries (Lancioni, Smith and Oliva 2000; Gregory, Karavdic and Zou 2007; Alon, Jaffe, Prange and Vianelli 2016). From a marketing perspective, in recent years both manufacturers and retailers have had the possibility to become e-retailers, targeting consumers in different countries and selling their products 
through online stores. An increasing number of online shoppers accompanies the positive trend in the number of e-retailers. Some recent statistics show that in 2021, the number of global digital buyers will be over 2.14 billion people, up from 1.66 billion people shopping online in 2016 (Statista 2018a and 2018b). However, despite the global growth of online shopping, one can still note a very pronounced divergence between countries, in terms of in the percentage of people that shop on-line. Asia has the highest number of internet users (almost 2 billions), but with a penetration rate of 49.7 only, followed by Europe (659.6 millions), Latin America / Caribbean (404.2 millions) and United States (320.0 millions) with a penetration rate of $80.2 \%, 62.4 \%$ and $88.1 \%$ respectively (Internet World Stats 2018). The European market is more heterogeneous, and differences between countries are significant. According to Eurostat (2018), the highest percentage of e-shoppers can be found in United Kingdom (82\% of the population), followed by North European countries, while the lowest percentage can be found in Italy (32\%), Bulgaria (18\%), and Romania (16\%).

Despite the increasing number of consumers doing online shopping, studies on this area are still limited and researchers have called for more research (Ashraf, Thongpapanl, Menguc and Northey 2017). This is particularly evident in a context of cross-cultural analysis of consumer behavior. In fact, in a context of e-shopping, e-retailers' strategies would not only be affected by the different adoption rates across different countries (Ashraf, Thongpapanl and Auh 2014), but also by cultural differences that shape eshoppers' behavior. More specifically, when considering the role of national cultures on technology adoption, two of the Hofstede strongest statements are related to uncertainty avoidance and individualism / collectivism. Hofstede (2001) defines uncertainty avoidance as a dimension that reflects the extent to which the members of a culture feel threatened by ambiguous or unknown situations; individualism is defined as the degree of interdependence a society maintains among its members: in individualist societies people are supposed to look after themselves and their direct family members, while collectivistic societies are strongly connected with a group (extended family, friends, colleagues, etc.). According to Choi and Geistfeld (2004), in a context of online-shopping higher levels of uncertainty avoidance may result in higher levels of perceived risk, reducing the likelihood to adopt online shopping as a medium to acquire products. Similarly, greater collectivism may facilitate the use of ecommerce, because the in-group collectivistic approach may lead to sharing opinions and information, decreasing the perceived risk associated with shopping online.

In conclusion, on-line retailers must decide whether to standardize or adapt their marketing strategy to the foreign consumer markets, when considering going global, as the adaptation / standardization dilemma plays a central role in the internationalization of retailing (Alon, Jaffe, Prange and Vianelli, 2016). The objective of this article is not only to locate differences in on-line shopping behavior between English, Italian, and Chinese consumers, but also to explain these differences, through cultural dimensions such as Hofstede's cultural indexes and Wursten and Fadrhonc's (2012) regional clusters.

\section{Research methodology}

A discriminant analysis was conducted on English, Italian and Chinese consumers, based on eighteen behavioral variables, in order to illustrate the effect that a change of culture would have on a consumer's on-line shopping behavior. Concerning the 
analysis, the behavioral variables were classified in a descending lexicographic order of their discriminating power, between these cultures. After running the discriminant analysis, a factorial analysis of the eighteen behavioral describers was also run, to organize the latter into a smaller number of factors that are mutually exclusive, and very exhaustive.

With respect to sampling, 1161 respondents were analyzed, more specifically, 443 Italian consumers, 250 British consumers, and 468 Chinese consumers. A mixed method was used in the sampling procedure, as a non-probabilistic method was used in selecting English participants through convenience sampling, while a probabilistic procedure was adopted in both Italy and China, namely cluster sampling. The samples collected were calibrated to ensure they were demographically balanced, so that a difference in the results between the countries studied would more likely be due to a cultural difference than to a demographical difference. Finally, the questionnaire was written originally in English, and then translated to both Italian and Chinese.

We decided to investigate these countries for two reasons. First, China, Italy and England provide a diverse set with varying levels of Hofstede's cultural dimensions. Individualism in China has a score of 20 (being a collectivistic society), while in Italy and England the score is 76 and 89 respectively, showing the presence of a highly individualistic culture. Please note that in most of our interpretation, we are not making a distinction here between the North and the South of Italy, as they are similar with respect to all cultural indicators (Wursten and Fadrhonc, 2012), except for individualism, where the former is more individualistic than the latter. Concerning uncertainty avoidance, China is more similar to England, with a score of 30 and 35 respectively, while Italy has a score of 76 . Not only the selected countries are culturally different, but they also have a different degree of maturity of online shopping, as pointed out in the introduction. The second reason for studying these three countries is the fact that they belong to different geographic clusters, as England is part of the "Contest" cluster, China is part of the "Family" cluster, Northern-Italy is part of the "Solar" cluster, and Southern-Italy is part of the "Pyramid" cluster (Wursten and Fadrhonc, 2012), which suggests potential cultural differences.

The research objective is both "descriptive", because the study describes consumers' on-line shopping behavior in each culture, and "causal", because it investigates the cause-to-effect relationships between culture and on-line shopping behavior. The variables/questions introduced in this study were selected based on their aptitude to point-out the effect of culture on on-line shopping behavior, as will be developed under the "findings" section. The research approach adopted is a survey that uses a questionnaire as an instrument. Four types of scales were used to measure eighteen behavioral variables. The first one is a Likert scale to measure respondents' opinions, where " 5 " stands for "strongly Agree" and " 1 " for "strongly disagree", and was used for instance to measure the variable "Knowledge of a specific Brand would increase my confidence in buying it online", which falls under the $2^{\text {nd }}$ factor as can be seen on Table-1. The second scale measures the likelihood of an event happening, where the probability of the event of interest occurring ranges from zero to $100 \%$, and was used for instance to measure the variable "How Likely would you be influenced by Family when shopping online?", which falls under the $3^{\text {rd }}$ factor as can be seen on Table- 1 . Then, the third type of scale is built on a polarized continuum, where " 5 " and " 1 " are 
the positive and the negative ends respectively, and was used for instance to measure the variable "What product quality are you Expecting from an On-Line Purchase?", where " 5 " and "1" meant "High" and "Low" Product Quality, respectively. Finally, the fourth type of scale is built on a continuum from " 1 " to " 4 " where respondents were given four choices of answers, and " 4 " stands for the highest answer possible, while " 1 " stands for the lowest, as is the case for the variables "How much do you spend on average for online shopping per month", or "How often do you shop online?" (Under $1^{\text {st }}$ Factor - see Table-1), "What is your expectation for delivery time?" (Under $4^{\text {th }}$ Factor - see Table-1), (Under $1^{\text {st }}$ Factor - see Table-1). A respondent that has code " 3 " for his/her answer to the latter question for instance would mean that $\mathrm{s} / \mathrm{he}$ shops more frequently on-line than a respondent that has code " 2 ".

\section{Findings}

Factorial analysis revealed that five distinct factors of on-line shopping behavior were being compared between the markets stated above (Table 1).

Indeed, the $1^{\text {st }}$ factor "Usage of, and familiarity with on-line shopping" differentiated between English and Chinese consumers. For instance, for the variable "To what extent people prefer on-line shopping to physical stores" (PreOnli), as Mean $_{\text {PreOnli-England }}=3.42>$ Mean $_{\text {PreOnli-China }}=2.73$, on a scale, from " 1 " to " 5 " $(1=$ Strongly prefer physical stores, and $5=$ Strongly prefer on-line shopping). This result is supported by the literature; As England is part of the Contest cluster that is characterized by a high level of masculinity, it values decisiveness at the expense of dialog and "growing insight" (Wursten and Fadrhonc, 2012); as a result, English consumers would appreciate limiting the human interaction with the vendors (by shopping on-line), more than Italian and Chinese consumers would, as the latter fall under societies with an average rather than high level of Masculinity.

Concerning the $2^{\text {nd }}$ factor that is "Trust $\&$ Product Quality Expectation, when Shopping On-Line", it differentiates between Italian consumers on one side, and Chinese and English consumers on the other side", through its variables namely, "payment security", and "how knowledge of a brand, encourages its purchase on-line" (BrdKno), as Mean BrdKno-Italy $=4.00>$ Mean BrdKno-England $=3.05 \cong$ Mean BrdKno-China $=3.05$ on a scale, from " 1 " to "5" ( 1 = Strongly Disagree, and $5=$ Strongly Agree $)$. Considering the literature the Italian culture is characterized by high Uncertainty Avoidance Index (UAI), therefore one would expect Italian consumers to have a lower trust in the payment system than both Chinese and English consumers, that are part of cultures with a low UAI (Wursten and Fadrhonc, 2012). Surprisingly, our results show the opposite, as Italian consumers are more confident about on-line payment security than English or Chinese consumers are, which suggests further investigation to explain this discrepancy that could be due to a non-cultural factor. On the other hand, Italian look for branded products more than English or Chinese consumers, to decrease uncertainty about online shopping, which fits our expectation. 


\begin{tabular}{|c|c|c|c|c|}
\hline Factors / Variables & England & China & Italy & $A N O V A$ \\
\hline \multicolumn{5}{|l|}{$\begin{array}{l}\text { 1 }{ }^{\text {st }} \text { Factor: Usage of, and Familiarity with, On-Line } \\
\text { Shopping. }\end{array}$} \\
\hline Number of years of online shopping. & 2.25 & 1.75 & 2.02 & 0.000 \\
\hline How often do you shop On-Line? & 2.59 & 2.35 & 2.60 & 0.000 \\
\hline To what extent do you prefer online shopping? & 3.42 & 2.73 & 2.47 & 0.000 \\
\hline $\begin{array}{l}\text { How much do you spend on average for online } \\
\text { shopping per month }\end{array}$ & 2.29 & 1.92 & 1.73 & 0.000 \\
\hline \multicolumn{5}{|l|}{$\begin{array}{l}2^{\text {nd }} \text { Factor: Trust \& Product Quality Expectation, when } \\
\text { Shopping On-Line. }\end{array}$} \\
\hline $\begin{array}{l}\text { When shopping online, how confident are you that your } \\
\text { payment information is secure? }\end{array}$ & 3.13 & 2.99 & 3.42 & 0.000 \\
\hline $\begin{array}{l}\text { Knowledge of a specific Brand would increase my } \\
\text { confidence in buying it online }\end{array}$ & 3.05 & 3.05 & 4.00 & 0.000 \\
\hline $\begin{array}{l}\text { What product quality are you Expecting from an On- } \\
\text { Line Purchase? }\end{array}$ & 3.29 & 3.47 & 3.68 & 0.000 \\
\hline \multicolumn{5}{|l|}{$\mathbf{3}^{\text {rd }}$ Factor: Influencers of On-Line Shoppers } \\
\hline $\begin{array}{l}\text { How Likely would you be influenced by Family when } \\
\text { shopping online? }\end{array}$ & .57 & .37 & .22 & 0.000 \\
\hline $\begin{array}{l}\text { How Likely would you be influenced by Friends when } \\
\text { shopping online? }\end{array}$ & .63 & .52 & .40 & 0.000 \\
\hline $\begin{array}{l}\text { How Likely would you be influenced by Social Media } \\
\text { when shopping online? }\end{array}$ & .59 & .35 & .37 & 0.000 \\
\hline $\begin{array}{l}\text { To what extent are you influenced by online } \\
\text { advertising? }\end{array}$ & 3.23 & 2.51 & 1.87 & 0.000 \\
\hline \multicolumn{5}{|l|}{$\begin{array}{l}4^{\text {th }} \text { Factor: Purchase and Post-Purchase Elements of } \\
\text { On-Line Shopping }\end{array}$} \\
\hline $\begin{array}{l}\text { How much time does it take you to choose a product } \\
\text { when shopping online? }\end{array}$ & 2.71 & 2.51 & 2.80 & 0.001 \\
\hline $\begin{array}{l}\text { What is your expectation (acceptable standard) for } \\
\text { delivery time? }\end{array}$ & 3.27 & 2.01 & 3.24 & 0.000 \\
\hline $\begin{array}{l}\text { How Difficult is it to return a product Purchased On- } \\
\text { Line? }\end{array}$ & 3.42 & 2.71 & 3.06 & 0.000 \\
\hline \multicolumn{5}{|l|}{$\begin{array}{l}5^{\text {th }} \text { Factor: Perceived Competitive Advantages of On- } \\
\text { Line Shopping }\end{array}$} \\
\hline $\begin{array}{l}\text { How Likely would you Shop On-Line mainly to Save } \\
\text { Money? }\end{array}$ & .47 & .27 & .51 & 0.000 \\
\hline $\begin{array}{l}\text { How Likely would you Shop On-Line mainly to have a } \\
\text { Wider Brand Variety? }\end{array}$ & .61 & .45 & .40 & 0.001 \\
\hline $\begin{array}{l}\text { How Likely would you Shop On-Line mainly to Save } \\
\text { Time? }\end{array}$ & .69 & .62 & .57 & 0.101 \\
\hline $\begin{array}{l}\text { How Likely would you Shop On-Line mainly for its } \\
\text { ease in comparing products? }\end{array}$ & .44 & .35 & .40 & 0.109 \\
\hline
\end{tabular}

Table 1: Group Means and ANOVA's P-values

The $3^{\text {rd }}$ factor that is "Influencers of on-line shoppers", also differentiates between English and Chinese consumers, through its variables namely, "Family's 
influence"(Family), "Friends' influence", "on-line advertising's influence on on-line shoppers", and "social-media's influence". For instance, the probability that a consumer from each country would choose family as a mean of influence was: Mean $_{\text {Family-England }}=57 \%>$ Mean Family-China $_{\text {F }}=37 \%$. In this case as well, results require further analysis, as China is part of the Family clusters that is characterized by a high Power Distance Index (PDI), where older people are respected and there opinion heard (Wursten and Fadrhonc, 2012), therefore, it is expected that Chinese consumers would score higher on this variable than English consumers, since they would value more their parents/family's opinion when shopping, which is not the case from our results! Is the new generation of Chinese consumers changing a thousands years old culture?

Concerning the $4^{\text {th }}$ and the $5^{\text {th }}$ factor, the results are split: According to the discriminant analysis procedure, there are variables that differentiate between English and Chinese consumers, such as the variable "difficulty to return products purchased on-line", that falls under the $4^{\text {th }}$ factor that is, "Purchase and Post-purchase elements of on-line shopping" (see Table-1). The other variable that differentiates between English and Chinese consumers is "variety as a competitive advantage", that falls under the $5^{\text {th }}$ factor that is, "perceived competitive advantages of on-line shopping" (see Table-1). Contrarily, other variables of the $4^{\text {th }}$ and the $5^{\text {th }}$ factors differentiate between Chinese consumers on one hand, and Italian and English consumers on the other hand, such as the variables "time required to choose a product on-line" (Choosing) and "expected delivery time" that fall both of them under the $4^{\text {th }}$ factor, and "opportunity to save money" (Save), that falls under the $5^{\text {th }}$ factor (see Table-1). Indeed, Mean Save-China $=$ $27 \%<$ Mean Save-England $=47 \% \cong$ Mean Save-Italy $=51 \%$, while Mean Choosing-China $=2.51<$ Mean Choosing-England $=2.71 \cong$ Mean Choosing-taly $=2.80$. These results can be explained through cultural indexes. For instance, the variable "Choosing", was studied in this paper based on the following logic: The Solar or the Pyramid clusters that Northern and southern Italians belong to respectively, tend to have a higher UAI than in the Contest or Family clusters, that host the English and the Chinese cultures, respectively (Wursten and Fadrhonc, 2012). Since expressing emotions is more common in societies with a high UAI (Wursten and Fadrhonc, 2012), one would expect Italian consumers to be more involved emotionally when shopping, and to pursue a hedonic objective from their shopping experience, while the English and Chinese consumers would be expected to be more utilitarian and interested in acquiring the product only. As a result, the latter should decide about their purchase in a shorter time than the Italians would. Hence, our results confirm our expectation.

On the other hand, the variable "Save" that falls under the $5^{\text {th }}$ factor, and differentiates Chinese consumers from English and Italian consumers, can be explained by the fact that China is part of the Family clusters that is characterized by a high level of Collectivism, which makes Chinese consumers are more "Face-conscious", meaning that they fear "losing face" (Wursten and Fadrhonc, 2012). As a result, Chinese consumers would be less likely to admit shopping on-line in order to save money, as a such declaration may make them lose face. This would explain why China scores the least on this question, compared to English and Northern-Italian consumers (where our respondents come from), that both tend to have a higher level of Individualism. 
It is interesting to note from the findings above, that with respect to certain variables, English consumers are more similar to Chinese than to Italian consumers, such is the case for the variable "BrdKno" for instance (see numbers under $2^{\text {nd }}$ factor). While with respect to other variables, Italians consumers are more similar to Chinese than to English consumers, such is the case for the variable "PreOnli" among other variables, as can be seen from the numbers stated above. These results question the assumption, and go against the expectation that countries that share a geographical proximity would have a relatively similar consumer behavior.

Finally, there are variables that were not found to be significant in differentiating between the cultures stated above, such as the "opportunity to save time" (SaveTime), or the "ease to compare products" (ComProd), as the main reasons for shopping on-line, which both fall under the $5^{\text {th }}$ factor that is, the "perceived competitive advantages of on-line shopping". In fact, the probability that a consumer from each country would believe that the variable "ComProd" is a main competitive advantage of on-line shopping, is as follows: Mean Comprod-England $=44 \% \cong$ Mean Comprod-ftaly $=40 \% \cong$ Mean ComProd-China $=35 \%$, while the numbers for the variable "Save-Time" are as follows: Mean $_{\text {SaveTime-England }}=69 \% \cong\left(\right.$ Mean $_{\text {SaveTime-Italy }}=57 \% \cong$ Mean $_{\text {SaveTime-China }}=$ $62 \%)$. These results mean that all three cultures agree on the importance of "saving time" as a competitive advantage of shopping on-line over shopping at a physical store, while most consumers in these cultures do not view the "ease to compare products" as a main competitive advantage of on-line shopping.

Another task the Discriminant analysis accomplishes is the prediction of people's group membership based on their answers to the survey. In other words, by merely examining a person's answers to the questionnaire, one could predict whether the respondent is English, Chinese or Italian. This is equivalence to claiming that after this Discriminant analysis, it is possible to know what to expect as a behavior, from people belonging to each of these three cultures, with respect to the eighteen variables considered. The results show that $80.2 \%$ of respondents were classified correctly, as English, Chinese or Italian, simply by scrutinizing the type of answers they have provided in the survey. This is a good hit ratio, as it increases the prediction accuracy by $47.2 \%$ compared to allocating people randomly to either group, which would have resulted in a $33.33 \%$ chance of being part of either group of consumers, as this study considers three groups namely, English, Chinese or Italian consumers. This prediction accuracy can be extended to the whole population, and not remain restricted to respondents in the sample. To do so, a Leave-One-Out validation method was used, and revealed that the accuracy for people out of the sample will remain as high as 78.9\%, which is still an increase of the prediction accuracy by $45.9 \%$ compared to allocating people randomly (33.33\% accuracy).

\section{Conclusions and practical implications}

On-line retailers cannot duplicate abroad their home marketing strategy, as most of the needs e-shoppers wish to fulfill could diverge between markets. The fundamental factors differentiating consumer's online shopping behavior in different countries, must be identified and taken into consideration when setting e-retailing strategies for a foreign market, in order to decide about the degree of adaptation needed. While several 
of the variables studied clearly applied to all product categories, a couple of these variables could be the subject of future research to unveil to what extent the latter could be industry specific. Nevertheless, both some specialized retailers, and department stores with wide assortments, would value the results of this research as it depicts divergences as well as similarities between the cultures studied, which draws the line for where standardization of the on-line marketing strategies should stop, and where adaptation should start.

\section{References}

Alon I., Jaffe E., Prange C. and D. Vianelli (2016). Global Marketing: Contemporary theory, practice and cases. New York: Routledge - Taylor \& Francis.

Ashraf A.R., Thongpapanl N., Menguc B. and G. Northey (2017). "The Role of M-Commerce Readiness in Emerging and Developed Markets" Journal of International Marketing, 25(2) 25-51.

Ashraf, A.R., Thongpapanl N. and S. Auh (2014). "The Application of the Technology Acceptance Model Under Different Cultural Contexts: The Case of Online Shopping Adoption" Journal of International Marketing, 22 (3), 68-93.

Choi J. and L.V. Geistfeld (2004). "A cross-cultural investigation of consumer e-shopping adoption" Journal of Economic Psychology, 25 (6), 821-838.

Eurostat (2018). E-commerce statistics for individuals, http://ec.europa.eu/eurostat/statisticsexplained/index.php/E-commerce_statistics_for_individuals, retrieved on January 17, 2018.

Gregory, G., Karavdic, M. and S. Zou (2007). "The Effects of E-Commerce Drivers on Export Marketing Strategy" Journal of International Marketing, 15 (2), 30-57.

Hofstede G. (2001). Culture's Consequences: Comparing Values, Behaviors, Institutions and Organizations Across Nations. 2nd Edition, Thousand Oaks CA: Sage Publications.

Internet World Stats (2018). Internet Users Statistics in 2017, http://www.internetworldstats.com/stats.htm, retrieved on January 17, 2018.

Lancioni, R.A., Smith, M.E. and T.A. Oliva (2000). "The Role of the Internet in Supply Chain Management" Industrial Marketing Management, 29 (1), 45-56.

Statista (2018a). Number of digital buyers worldwide from 2014 to 2021, https://www.statista.com/statistics/251666/number-of-digital-buyers-worldwide/, retrieved on January 17, 2018.

Statista (2018b). Global markets with the highest online shopping penetration rate, https://www.statista.com/statistics/274251/retail-site-penetration-across-markets/, retrieved on January 17, 2018.

Wursten, H. and T. Fadrhonc (2012). International marketing and culture, Itim International, 1-9. 